\title{
BMJ Open Development of chronic kidney disease influenced by serum urate and body mass index based on young-to-middle- aged Japanese men: a propensity score- matched cohort study
}

\author{
Akihiro Kuma (D) , ${ }^{1,2}$ Kosuke Mafune (D) , ${ }^{3}$ Bungo Uchino, ${ }^{4}$ Yoko Ochiai, ${ }^{4}$ \\ Kazuhiko Enta, ${ }^{5}$ Akihiko Kato ${ }^{2}$
}

To cite: Kuma A, Mafune K, Uchino B, et al. Development of chronic kidney disease influenced by serum urate and body mass index based on young-to-middleaged Japanese men: a propensity score-matched cohort study. BMJ Open 2022;12:e049540. doi:10.1136/ bmjopen-2021-049540

- Prepublication history and additional supplemental material for this paper are available online. To view these files, please visit the journal online (http://dx.doi.org/10.1136/ bmjopen-2021-049540).

Received 26 January 2021 Accepted 19 January 2022

Check for updates

(c) Author(s) (or their employer(s)) 2022. Re-use permitted under CC BY-NC. No commercial re-use. See rights and permissions. Published by BMJ.

For numbered affiliations see end of article.

Correspondence to

Dr Akihiro Kuma;

kuma-aki@med.uoeh-u.ac.jp

\section{ABSTRACT}

Objective To investigate the association between serum uric acid (SUA) level and body mass index (BMI) on the development of chronic kidney disease (CKD) in working men aged 20-60 years.

Design Retrospective cohort study.

Setting Data from employees' annual health check-ups were collected from two companies in 2009 and 2014.

Participants A total of 16708 working men were recruited. We excluded participants with missing essential data $(\mathrm{N}=7801)$, who had basal estimated glomerular filtration rate $(\mathrm{eGFR})<60.0 \mathrm{~mL} / \mathrm{min} / 1.73 \mathrm{~m}^{2}$ and $/$ or proteinuria ( $\mathrm{N}=698$ ) or with the absence of follow-up data $(\mathrm{N}=2)$.

Primary outcome eGFR $<60 \mathrm{~mL} / \mathrm{min} / 1.73 \mathrm{~m}^{2}$ and $/$ or proteinuria $(\geq 1+)$ in 2014 (defined as incident CKD). Results The cut-off values of SUA for incident CKD were $6.6 \mathrm{mg} / \mathrm{dL}$ in both young (20-39 years old) and middleaged (40-60 years old) men analysed by receiver operator characteristics. ORs for incident CKD were assessed on propensity score-matched (1:1) cohorts. In young participants $(\mathrm{N}=1938)$, after propensity score matching, a coexistence of high-level SUA ( $\geq 6.6 \mathrm{mg} / \mathrm{dL}$ ) and overweight $\left(\mathrm{BMI} \geq 25 \mathrm{~kg} / \mathrm{m}^{2}\right)$ was a significant risk factor of incident CKD (OR=2.18, 95\% Cl 1.10 to 4.31, p=0.025), but highlevel SUA was not an independent risk factor without overweight status $(p=0.174)$. In middle-aged participants ( $N=2944)$ after propensity score matching, high-level SUA was a significant risk factor of incident CKD both with or without overweight $(\mathrm{OR}=1.44,95 \% \mathrm{Cl} 1.02$ to 2.04, $\mathrm{p}=0.037 ; \mathrm{OR}=1.32,95 \% \mathrm{Cl} 1.01$ to $1.73, \mathrm{p}=0.041$, respectively).

Conclusion These findings suggest that high-level SUA is strongly associated with incident CKD in overweight young adult men.

\section{INTRODUCTION}

High levels of serum uric acid (SUA) or overweight/obesity are well-known risk factors for incident chronic kidney disease (CKD). Uric acid (UA) is the final oxidation product of purine metabolism, accompanying the
Strengths and limitations of this study

- This is the first study to investigate the role of high serum uric acid level as a risk factor for the development of chronic kidney disease according to age and overweight status for apparently healthy workers.

- Participants were propensity score matched (1:1) to eliminate covariants owing to it being a retrospective cohort.

- The main limitation was that since this study was based on an observational design, we could not rule out residual confounding by several factors, which were not collected in our participants.

production of reactive oxygen species by xanthine oxidoreductase. Several factors (dietary intake of purine, sugars and fructose as well as kidney dysfunction and genetics) cause overproduction or under excretion of UA, leading to an abnormally high level of SUA. ${ }^{1}$ However, allopurinol, a hypoxanthine analogue, slows down the progression of kidney disease. ${ }^{2}$ Recent studies have indicated that hyperuricaemia may directly contribute to the development or progression of kidney disease, cardiovascular disease and hypertension. ${ }^{3-5}$ In a 9-year follow-up study with more than 13000 healthy participants, every $1 \mathrm{mg} / \mathrm{dL}$ increase in basal SUA level was strongly associated with a $7 \%$ increased risk for incident CKD. ${ }^{6}$ Furthermore, from a meta-analysis involving 190000 participants with basal normal kidney function, the risk for incident CKD was found to be two-fold in the presence of hyperuricaemia. ${ }^{7}$

Obesity is also associated with the progression of CKD. ${ }^{8-11}$ Furthermore, our group showed that abdominal adiposity was a risk for incident CKD in young adult men. ${ }^{12}$ Both obesity and abdominal obesity increase with 
age; but abdominal obesity was found to be more strongly affected by ageing. ${ }^{13} 14$ Thus, we investigated whether there could be a different influence on kidney function according to age and metabolic profiles. Patients with metabolic syndrome have hypertension, elevated lowdensity lipoprotein cholesterol and triglyceride levels, insulin resistance and urinary albuminuria, which affect incident CKD. Additionally, the Chronic Kidney Disease Japan Cohort (CKD-JAC) study in Japan showed that urine albumin and body mass index (BMI) are significantly associated with a $50 \%$ decline of estimated glomerular filtration rate (eGFR) in patients with CKD, but not SUA. ${ }^{15}$

Previous reports have indicated the evidence of hyperuricaemia for kidney disease in middle-aged to older individuals. However, it is unclear whether overweight and/ or high level of SUA are associated with incident CKD in young populations. This study aimed to test the relationship between incident CKD and the combination of high levels of SUA and BMI, during a 5-year observation period in otherwise healthy men.

\section{METHODS}

\section{Study participants}

This retrospective cohort study analysed annual health check-up data of workers obtained in 2009 and 2014 in Japanese industrial enterprises. Male workers aged 20-60 years at baseline (in 2009) with annual health check-up

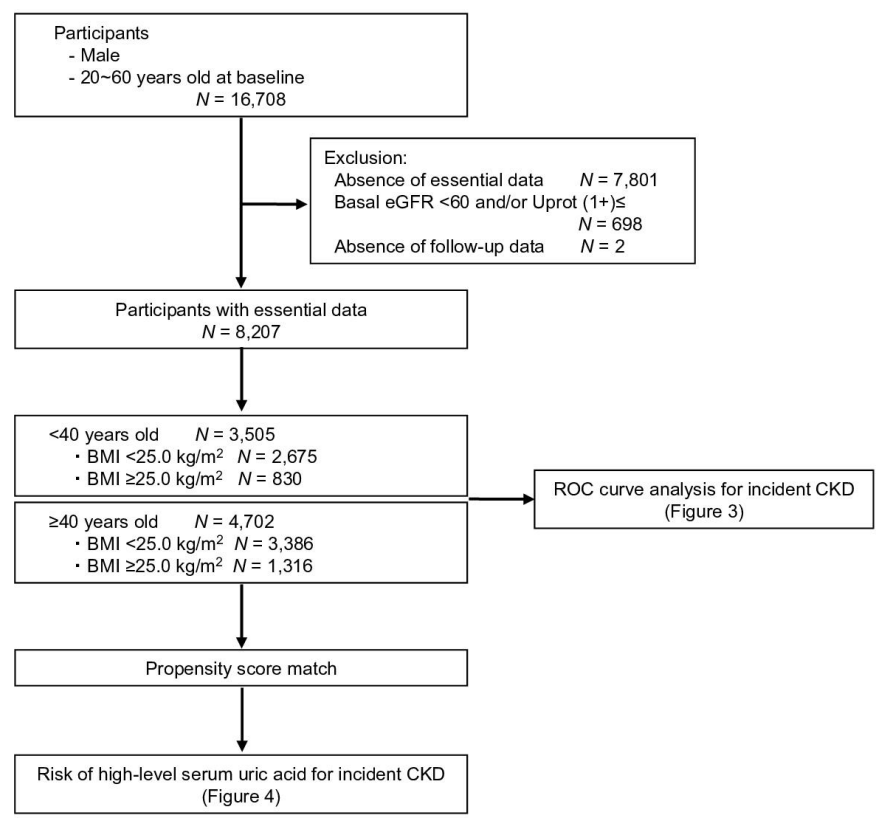

Figure 1 Flowchart of study participants. Essential data are the estimated glomerular filtration rate (eGFR, $\mathrm{ml} / \mathrm{min}$ per $1.73 \mathrm{~m}^{2}$ ), body mass index, high-density lipoprotein cholesterol, triglycerides, uric acid, haemoglobin A1c, systolic/diastolic blood pressure, urinalysis and interview sheet. Follow-up data are essential data 5 years after baseline. CKD, chronic kidney disease; eGFR, estimated glomerular filtration rate; Uprot, proteinuria with dipstick testing; ROC, receiver operating characteristic. data $(\mathrm{N}=16708)$ were recruited (figure 1$)$. Workers with missing essential data $(\mathrm{N}=7801)$, basal eGFR $<60 \mathrm{~mL} /$ min per $1.73 \mathrm{~m}^{2}$ and proteinuria $(\geq 1+$, with dipstick test) $(\mathrm{N}=698)$, and with the absence of 5 -year follow-up data $(\mathrm{N}=2)$ were excluded.

In this study, we divided the participants into two age groups as follows: a young group, which was composed of participants aged $<40$ years, and a middle-aged group, which was composed of participants aged 40-60 years. Furthermore, they were divided into two groups according to BMI $\left(<25.0 \mathrm{~kg} / \mathrm{m}^{2}\right.$ or $\left.\geq 25.0 \mathrm{~kg} / \mathrm{m}^{2}\right)$ in each age group.

\section{Patient and public involvement \\ No patient involved.}

\section{Annual health check-up}

In Japan, a law enacted by the Ministry of Health, Labour and Welfare requires all companies to provide employees an annual health check-up. For this study, we measured blood pressure (BP), height and body weight. BMI (kg/ $\mathrm{m}^{2}$ ) was calculated as body weight $(\mathrm{kg})$ divided by body height squared $\left(\mathrm{m}^{2}\right)$. Overweight/obesity is defined when BMI exceeds $25.0 \mathrm{~kg} / \mathrm{m}^{2}$, according to the WHO classification. Blood and urine tests were performed by a private laboratory company. eGFR was calculated using the following equation: eGFR $(\mathrm{mL} / \mathrm{min}$ per $\left.1.73 \mathrm{~m}^{2}\right)=194 \times$ serum creatinine $\mathrm{e}^{-1.094} \times$ age $^{-0.287} \cdot{ }^{16}$ This threevariable Japanese equation for eGFR has been assessed with isotope dilution mass spectrometry (IDMS)-modification of diet in renal disease (MDRD) study equation. Thus, this three-variable Japanese equation is more accurate for the Japanese population than other equations including the IDMS-MDRD study equation. Incident CKD was defined as an eGFR $<60 \mathrm{~mL} / \mathrm{min}$ per $1.73 \mathrm{~m}^{2}$ and/or the development of proteinuria in 2014. The presence of urine protein was tested using dipstick, and proteinuria was defined as urine protein 1+ or more. Alcohol consumption was defined as the habit of drinking alcohol for 6 or 7 days a week. The information on medication for hypertension or diabetes mellitus was collected from a self-interview sheet. The medication for diabetes mellitus included the usage of insulin.

\section{Statistical analysis}

The receiver operating characteristic (ROC) analysis was used to determine the appropriate cut-off value of SUA for incident CKD. A student $t$ test or $\chi^{2}$ test was performed to compare the two groups using Stata V.12SE (Stata, College Station, Texas). In the analysis of risk for incident CKD, we accounted for the non-equivalence of this cohort via propensity score matching with logistic regression (SAS V.9.2, SAS InstituteNorth Carolina) as previously reported. ${ }^{17}$ The propensity score represented the predicted probability that a given participant would have high-level SUA ( $\geq 6.6 \mathrm{mg} / \mathrm{dL})$, and participants who had high-level SUA at baseline were matched to control participants (SUA $<6.6 \mathrm{mg} / \mathrm{dL}$ at baseline) with a greedy algorithm. The propensity score model included the 
interaction of age, basal eGFR, BMI, high-density lipoprotein cholesterol, triglycerides, haemoglobin A1c, systolic $\mathrm{BP}$, a habit of smoking and habit of drinking alcohol.

Although this cohort was large $(\mathrm{N}=16708)$, we conducted 1:1 matching to avoid the possible bias of plural number-to-one matching. Propensity score matching was performed in six classifications, each as follows: (1) age under 40 years, (2) age under 40 years and BMI $<25.0 \mathrm{~kg} /$ $\mathrm{m}^{2}$, (3) age under 40 years and BMI $\geq 25.0 \mathrm{~kg} / \mathrm{m}^{2}$, (4) age 40-60 years, (5) age 40-60 years and BMI $<25.0 \mathrm{~kg} / \mathrm{m}^{2}$, (6) age $40-60$ years and BMI $\geq 25.0 \mathrm{~kg} / \mathrm{m}^{2}$. This process matched (1) 969, (2) 644, (3) 312, (4) 1472, (5) 950 and (6) 495 participants $(89.1 \%, 98.9 \%, 71.4 \%, 95.0 \%, 96.5 \%$ and $87.5 \%$ of high-level SUA participants, respectively) to the same number of control participants (SUA $<6.6 \mathrm{mg}$ / $\mathrm{dL}$ ) each (tables 1 and 2). The Kolmogorov-Smirnov test was performed to assess the normal distribution of the parameters, and all clinical parameters showed normal distribution. A covariate balance between matched high-level SUA participants and control participants was assessed using a two-tailed Student's t test, a $\chi^{2}$ test or a Fisher's exact test to confirm no statistical difference between the two groups and standardised mean differences (figure 2 and online supplemental figures 1 and 2). OR and $95 \% \mathrm{CI}$ for the prevalence of CKD were determined using logistic regression. A $p$ value $<0.05$ was considered statistically significant.

\section{RESULTS}

\section{Cut-off value of SUA}

To determine the appropriate cut-off value of SUA, ROC curve analysis was performed for incident CKD 5 years later (figure 3). During the 5-year follow-up, 148 (4.2\%) participants aged $<40$ years and $580(12.3 \%)$ participants aged 40-60 years developed incident CKD. In the young group, the cut-off SUA value was $6.6 \mathrm{mg} / \mathrm{dL}$ when the Youden index was at maximum, that is, 0.0992 (sensitivity of 0.4054 and specificity of 0.6938 ). Furthermore, in the middle-aged group, the appropriate cut-off SUA value was $6.6 \mathrm{mg} / \mathrm{dL}$ (Youden index 0.1314 , sensitivity of 0.4448 and specificity of 0.6866 ). Thus, we performed the subsequent analyses using the SUA cut-off value of $6.6 \mathrm{mg} / \mathrm{dL}$.

\section{Participant characteristics}

All participants were divided into two groups according to age first (under 40 years of age, online supplemental table 1 ; or aged 40-60 years, online supplemental table 2 ), then sorted according to BMI $\left(<25.0 \mathrm{~kg} / \mathrm{m}^{2}\right.$ or $\left.\geq 25.0 \mathrm{~kg} / \mathrm{m}^{2}\right)$, and their basal characteristics were compared. Significant differences were found in age, basal eGFR, high-density lipoprotein cholesterol level, triglyceride level, haemoglobin A1c level and systolic BP among the two groups in six classification each. Because this was a retrospective observational cohort study, there were several biases in participants' backgrounds. Thus, we adjusted for covariants by using propensity score matching (1:1) to remove biases. As shown in tables 1 and 2, there were no significant differences in each parameter.

Overweight with high-level SUA was a risk factor for incident CKD under $\mathbf{4 0}$ years

We analysed the risk of high-level SUA for incident CKD in participants classified by age and BMI (figure 4). In the young group, high-level SUA was not a risk factor for incident CKD (OR: $1.05,95 \%$ CI 0.69 to $1.59, \mathrm{p}=0.83$ ). However, high-level SUA became a risk for incident CKD if young participants were overweight (OR: 2.18, 95\% CI 1.10 to $4.31, \mathrm{p}=0.025$ ). In addition, high-level SUA was not a risk factor for incident $\mathrm{CKD}$ in non-overweight young participants (OR: 0.69 , 95\% CI 0.40 to $1.18, \mathrm{p}=0.17$ ). Furthermore, there was a significant interaction between overweight and high-level SUA ( $p$ for interaction=0.009).

\section{High-level SUA was a risk factor for incident CKD regardless of overweight status in middle-aged participants}

Furthermore, we analysed the risk for incident CKD in the middle-aged group (figure 4). In the middle-aged group, high-level SUA was a risk factor for incident CKD (OR: 1.32, 95\% CI 1.07 to $1.63, \mathrm{p}=0.009$ ). Participants with high-level SUA had a significant association with developing CKD even if they were not overweight (OR: $1.32,95 \%$ CI 1.01 to $1.73, \mathrm{p}=0.041$ ). Furthermore, when participants in this group were overweight, the risk for incident CKD was the same as those who were not overweight (OR: 1.44, 95\% CI 1.02 to 2.04, $\mathrm{p}=0.037$ ).

\section{DISCUSSION}

This retrospective study used health check-up data based on over 8000 men in Japan, and its findings may contribute to the prevention of incident CKD in apparently healthy and young populations. This study primarily found that high-level SUA was significantly associated with the risk of incident CKD in men aged $<40$ years who were overweight/obese. In addition, we found that highlevel SUA was significantly associated with the risk of incident CKD in middle-aged men regardless of overweight/ obese status.

High-level SUA, also known as hyperuricaemia, is common in patients with CKD. A previous study conducted on the US general population showed a CKD prevalence of $21.2 \%$ in men (SUA $>7.0 \mathrm{mg} / \mathrm{dL}$ ) and $21.6 \%$ in women (SUA $>5.7 \mathrm{mg} / \mathrm{dL}) .{ }^{18}$ An appropriate cut-off value of SUA for predicting incident CKD has been unclear. Thus, we performed ROC analysis for incident CKD first and found that $6.6 \mathrm{mg} / \mathrm{dL}$ of SUA level was a desirable value in both young-aged and middle-aged participants figure 3. In a retrospective study on Japanese patients with CKD, an SUA level over $6.0 \mathrm{mg} / \mathrm{dL}$ was significantly associated with progression to end-stage kidney disease, ${ }^{19}$ although hyperuricaemia for men is generally defined as SUA $>7.0 \mathrm{mg}$ / dL. Furthermore, a $1 \mathrm{mg} / \mathrm{dL}$ increase in SUA level was significantly associated with incident CKD. ${ }^{6}$ We expect 

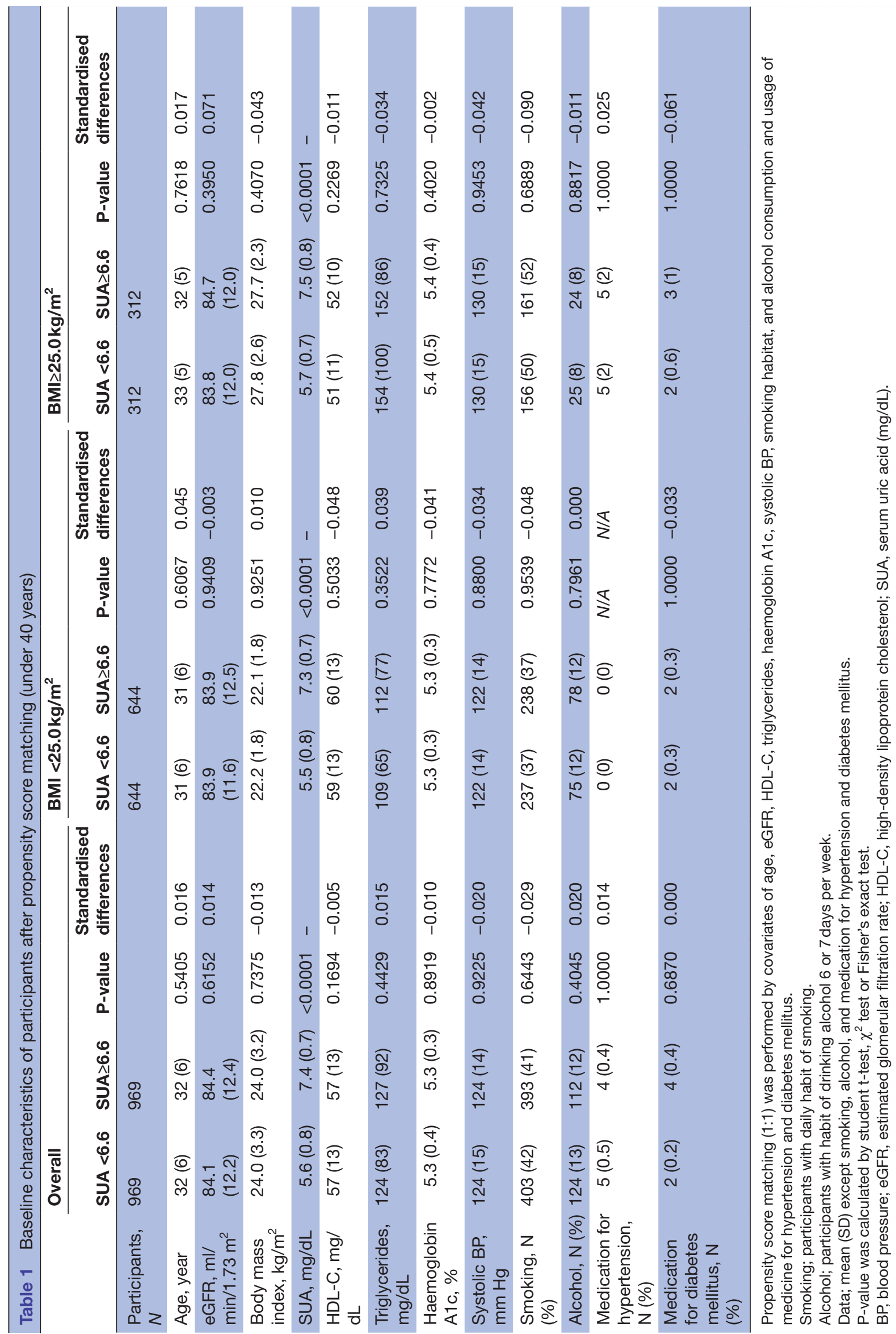

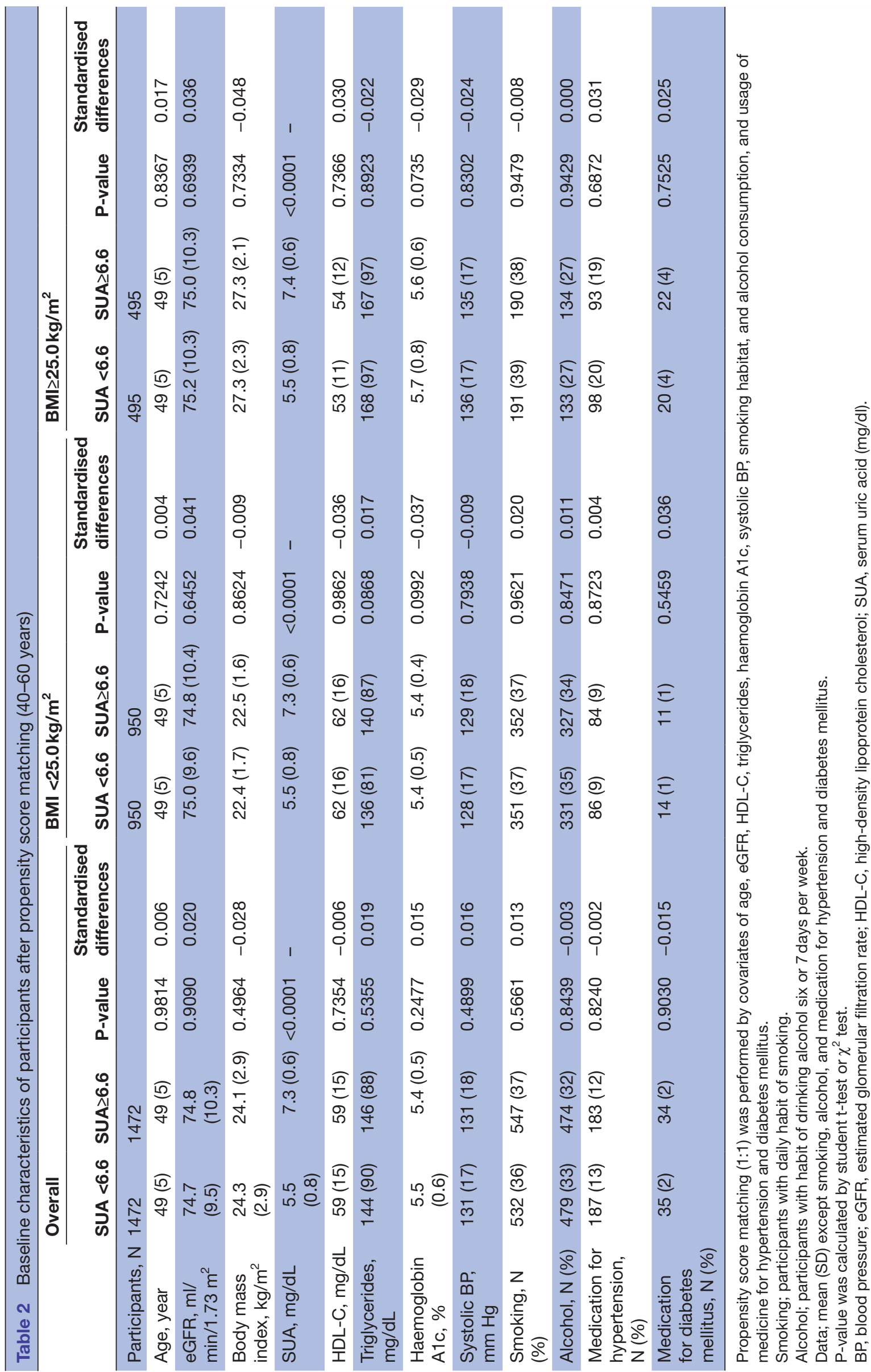


\section{A $<40$ years}

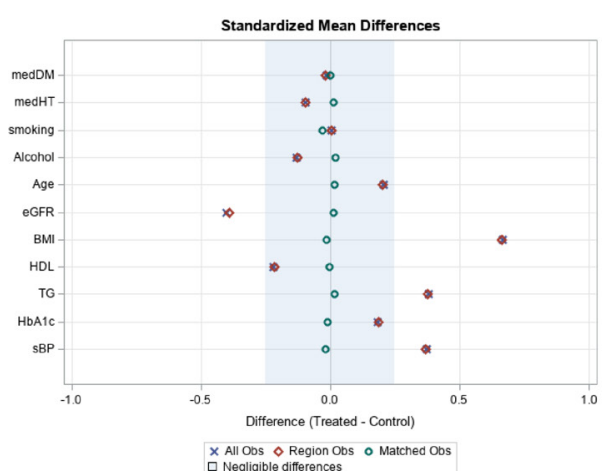

\section{$B \geq 40$ years}

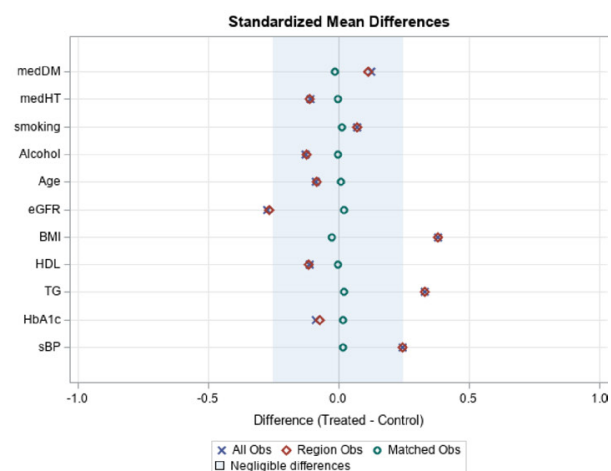

Figure 2 Standardized mean differences of covariances after propensity score matching. A) Participants aged $<40$ years at baseline $(\mathrm{N}=3,505)$ and $\mathrm{B})$ participants aged $\geq 40$ years at baseline $(\mathrm{N}=4,702)$. The propensity score model includes the interaction of age, basal eGFR, body mass index (BMI), high-density lipoprotein cholesterol (HDL), triglycerides (TG), haemoglobin A1c (HbA1c), systolic BP (sBP), a habit of smoking, a habit of drinking alcohol, usage of anti-hypertension medicine (medHT), and the usage of anti-diabetes mellitus medicine including insulin (medDM). Standardised mean differences of matched participants are shown in tables 1 and 2 and online supplemental tables 1 and 2 .

that our presented cut-off value for SUA may become an indicator for incident CKD.

Interestingly, from young (about 25 years old) to middle-aged (60 years old) adults in an Irish cohort, the prevalence of hyperuricaemia increased slowly; however, after age 60 years, the prevalence of hyperuricaemia rose sharply. ${ }^{20}$ In our cohort, the prevalences of hyperuricaemia in young $(<40$ years $)$ or middle-aged $(40-60$ years) participants were $31.0 \%$ and $53.0 \%$, respectively. Among participants in the non-overweight with hyperuricaemia group, no significant difference in basal SUA level was found between the young group $(7.3 \pm 0.7 \mathrm{mg} /$ $\mathrm{dL})$ and middle-aged group $(7.3 \pm 0.6 \mathrm{mg} / \mathrm{dL}) \quad(\mathrm{p}=0.94$, online supplemental figure 3). However, in middle-aged men, regardless of overweight/obese status, high-level SUA was found to be a significant risk factor for incident CKD when the OR was calculated after removing covariants (figure 4). Thus, high-level SUA may strongly affect eGFR decline in individuals aged $\geq 40$ years independent of overweight/obesity.

\section{A $<40$ years}

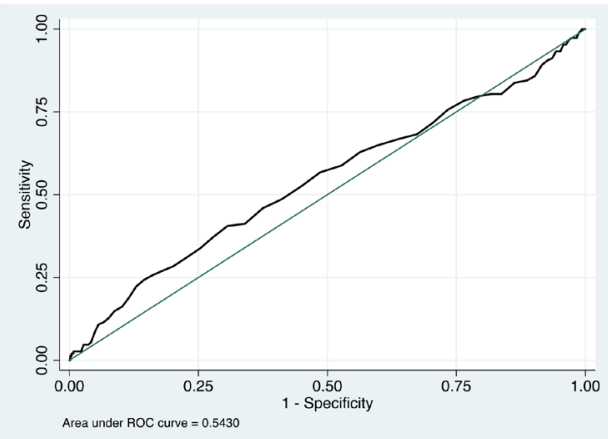

Overweight and abdominal adiposity are strongly associated with eGFR decline and proteinuria. ${ }^{12}$ 21-24 Furthermore, BMI is associated with a higher risk for cardiovascular disease (relative risk, 1.41) and mortality from heart failure (relative risk, 1.26) based on results from a systematic review and meta-analysis. ${ }^{25}$ Regarding biochemical mechanisms, subcutaneous adipose tissue and visceral adipose tissue play a role in the production of inflammation and oxidative stress markers such as interleukin- 6 and $\mathrm{C}$ reactive protein. ${ }^{26}$

We found that high-level SUA was not associated with incident CKD in young ( $<40$ years $)$ participants when participants were not overweight/obese (figure 4). BMI correlates with body fat in most individuals, but BMI does not distinguish body fat from muscle. In participants (mean age; 45 years) with normal metabolic status (without hypertension and diabetes mellitus), BMI was not a significant risk factor for incident CKD. ${ }^{27}$ On the contrary, from National Health and Nutrition Examination Survey data, abdominal

\section{$B \geq 40$ years}

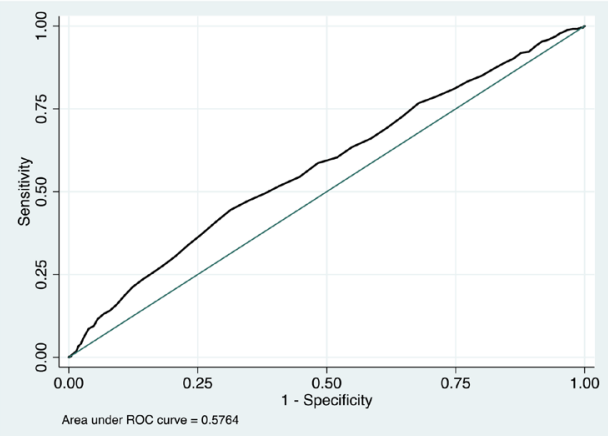

Figure 3 Receiver operating characteristic (ROC) curve analysis for incident CKD according to the level of serum uric acid A) Participants aged $<40$ years at baseline $(N=3,505)$ and $B$ ) participants aged $\geq 40$ years at baseline $(N=4,702)$. $R O C$ curves are calculated using the rate of incident CKD (eGFR<60 and/or development of proteinuria) 5 years later and the level of serum uric acid at baseline. CKD, chronic kidney disease; eGFR, estimated glomerular filtration rate. 


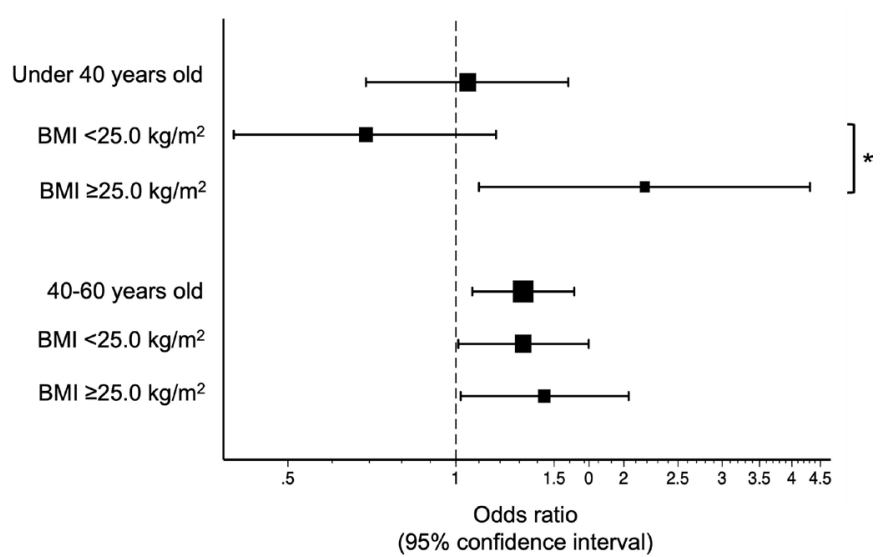

Figure 4 Risk of high-level SUA for incident CKD 5-year later ORs are calculated after propensity score matching. High-level SUA is not a risk factor in participants without obesity who are aged under 40 years. However, highlevel SUA was a risk factor in participants who are aged 40-60 years regardless of body mass index level. ${ }^{*} P$ for interaction=0.009. CKD, chronic kidney disease; SUA, serum uric acid.

obesity is associated with albuminuria in young adults despite being metabolically healthy. ${ }^{28}$ Thus, BMI alone may not be a suitable risk factor of incident CKD in healthy individuals.

In our cohort, in the young group with overweight/ obese status, high-level SUA was associated with a higher risk for incident CKD (figure 4), but we did not analyse parameters for abdominal obesity at this time. A study reported that the prevalence of abdominal adiposity was higher in middle-aged men than in young men. ${ }^{29}$ In middle-aged participants with BMI $<25.0 \mathrm{~kg} / \mathrm{m}^{2}$, high abdominal adiposity might affect kidney function decline. Therefore, greater abdominal adiposity increased the risk for incident CKD in middle-aged participants accompanied by high-level SUA when compared with young participants. Thus, high-level SUA was associated with incident CKD regardless of BMI level in middle-aged participants.

This study has several limitations. First, this study did not include data from women, because the number of female employees was relatively low $(\mathrm{N}=770)$ compared with that of male employees in the companies from which this data were gathered. Second, the effect of proteinuria might not be correctly evaluated, because urine samples collected were not always first-voided urine in the morning and were taken just one time each year. Third, we were not able to collect information on comorbidity and medication except the usage of antihypertension medication and antidiabetes mellitus medication including insulin from the self-interview sheet. Thus, the influence of other covariances such as comorbidity and medication was not completely removed. Finally, we used the single data of eGFR and proteinuria in 2014 to define CKD, although the Kidney Disease Improving Global Outcome guideline shows that CKD is diagnosed using various tests. However, our participants (workers) undertook an annual health check-up according to the law enacted by the Ministry of Health, Labour and Welfare in Japan. Thus, we could not request them to undergo health check-ups several times a year because they were not patients.

\section{CONCLUSIONS}

We found that high-level SUA $(\geq 6.6 \mathrm{mg} / \mathrm{dL})$ was a significant risk factor for incident CKD in men aged $<40$ years with an overweight/obese status (BMI $\geq 25.0 \mathrm{~kg} / \mathrm{m}^{2}$ ). In addition, high-level SUA was associated with incident CKD in middle-aged men regardless of whether they were overweight/obese. Thus, avoiding the combination of overweight and hyperuricaemia in young men, and hyperuricaemia in middle-aged men, may prevent CKD development.

\section{Author affiliations}

${ }^{1}$ Kidney Centre, Hospital of the University of Occupational and Environmental Health, Kitakyushu, Fukuoka, Japan

${ }^{2}$ Blood Purification Unit, Hamamatsu University Hospital, Hamamatsu, Shizuoka, Japan

${ }^{3}$ Department of Mental Health, Institution of Industrial Ecological Sciences, University of Occupational and Environmental Health, Kitakyushu, Fukuoka, Japan

${ }^{4}$ Health Promotion Centre, Yamaha Motor Co Ltd, Iwata, Shizuoka, Japan

${ }^{5}$ Health Care Centre, Central Japan Railway Company, Nagoya, Aichi, Japan

Acknowledgements We thank all staff at the Healthcare Centre in Central Japan Railway Company and the Health Promotion Centre in Yamaha Motor Co., Ltd. for supplying annual health check-up data. We would like to thank Editage (www. editage.com) for English language editing.

Contributors Designing research study: AKu, KM and AKa. Collecting data: AKu, $\mathrm{BU}, \mathrm{YO}$ and KE. Analysing data: AKu, KM and AKa. Manuscript writing: AKu and AKa. AKu acts as guarantor.

Funding The authors have not declared a specific grant for this research from any funding agency in the public, commercial or not-for-profit sectors.

Competing interests None declared.

Patient consent for publication Not applicable.

Ethics approval This study involves human participants and was approved by the ethical standards of the institutional committee (Hamamatsu University School of Medicine, No. E15-289). All individual participants were provided with a means to opt-out as follow: a notification for opt-out was displayed on the homepage of Hamamatsu University Hospital and in the clinics where all participants visited to undergo health check-up. The notification involved the usage of blood and urine data and the contents of the self-interview sheet and provided all participants to opt-out while the research was running if they did not want to participate in this study. This opt-out process did not affect the data collection and analysis.

Provenance and peer review Not commissioned; externally peer reviewed.

Data availability statement Data may be obtained from a third party and are not publicly available. The datasets generated during and/or analysed during the current study are not publicly available due to the rule of third parties which provided data to our facility but are available from corresponding author on reasonable request.

Supplemental material This content has been supplied by the author(s). It has not been vetted by BMJ Publishing Group Limited (BMJ) and may not have been peer-reviewed. Any opinions or recommendations discussed are solely those of the author(s) and are not endorsed by BMJ. BMJ disclaims all liability and responsibility arising from any reliance placed on the content. Where the content includes any translated material, BMJ does not warrant the accuracy and reliability of the translations (including but not limited to local regulations, clinical guidelines, terminology, drug names and drug dosages), and is not responsible for any error and/or omissions arising from translation and adaptation or otherwise. 
Open access This is an open access article distributed in accordance with the Creative Commons Attribution Non Commercial (CC BY-NC 4.0) license, which permits others to distribute, remix, adapt, build upon this work non-commercially, and license their derivative works on different terms, provided the original work is properly cited, appropriate credit is given, any changes made indicated, and the use is non-commercial. See: http://creativecommons.org/licenses/by-nc/4.0/.

\section{ORCID iDs}

Akihiro Kuma http://orcid.org/0000-0002-4242-7921

Kosuke Mafune http://orcid.org/0000-0001-7762-4143

\section{REFERENCES}

1 Chen C, Lü JM, Yao Q. Hyperuricemia-related diseases and xanthine oxidoreductase (XOR) inhibitors: an overview. Med Sci Monit 2016;22:2501-12.

2 Goicoechea M, de Vinuesa SG, Verdalles U, et al. Effect of allopurinol in chronic kidney disease progression and cardiovascular risk. Clin J Am Soc Nephrol 2010;5:1388-93.

3 Mallat SG, Al Kattar S, Tanios BY, et al. Hyperuricemia, hypertension, and chronic kidney disease: an emerging association. Curr Hypertens Rep 2016;18:74.

4 Watanabe S, Kang D-H, Feng L, et al. Uric acid, hominoid evolution, and the pathogenesis of salt-sensitivity. Hypertension 2002;40:355-60.

5 Zalawadiya SK, Veeranna V, Mallikethi-Reddy S, et al. Uric acid and cardiovascular disease risk reclassification: findings from NHANES III. Eur J Prev Cardiol 2015;22:513-8.

6 Weiner DE, Tighiouart $\mathrm{H}$, Elsayed EF, et al. Uric acid and incident kidney disease in the community. J Am Soc Nephrol 2008;19:1204-11.

7 Li L, Yang C, Zhao Y, et al. Is hyperuricemia an independent risk factor for new-onset chronic kidney disease?: a systematic review and meta-analysis based on observational cohort studies. BMC Nephrol 2014;15:122.

8 Chang Y, Ryu S, Choi Y, et al. Metabolically healthy obesity and development of chronic kidney disease: a cohort study. Ann Intern Med 2016;164:305-12.

9 Elsayed EF, Sarnak MJ, Tighiouart $\mathrm{H}$, et al. Waist-to-hip ratio, body mass index, and subsequent kidney disease and death. Am J Kidney Dis 2008;52:29-38.

10 Song Y-M, Sung J, Lee K. Longitudinal relationships of metabolic syndrome and obesity with kidney function: healthy twin study. Clin Exp Nephrol 2015;19:887-94.

11 Thomas G, Sehgal AR, Kashyap SR, et al. Metabolic syndrome and kidney disease: a systematic review and meta-analysis. Clin J Am Soc Nephrol 2011;6:2364-73.

12 Kuma A, Uchino B, Ochiai Y, et al. Relationship between abdominal adiposity and incident chronic kidney disease in young- to middleaged working men: a retrospective cohort study. Clin Exp Nephrol 2019;23:76-84.
13 Gutiérrez-Fisac JL, Guallar-Castillón P, León-Muñoz LM. Prevalence of general and abdominal obesity in the adult population of Spain, 2008-2010: the ENRICA study. Obesity Rev 2012;13:388-92.

14 Caspard H, Jabbour S, Hammar N, et al. Recent trends in the prevalence of type 2 diabetes and the association with abdominal obesity lead to growing health disparities in the USA: an analysis of the NHANES surveys from 1999 to 2014. Diabetes Obes Metab 2018;20:667-71.

15 Inaguma D, Imai E, Takeuchi A, et al. Risk factors for CKD progression in Japanese patients: findings from the chronic kidney disease Japan cohort (CKD-JAC) study. Clin Exp Nephrol 2017;21:446-56.

16 Matsuo S, Imai E, Horio M, et al. Revised equations for estimated GFR from serum creatinine in Japan. Am J Kidney Dis 2009;53:982-92.

17 Kuma A, Mafune K, Uchino B, et al. Alteration of normal level of serum urate may contribute to decrease in estimated glomerular filtration rate decline in healthy Japanese men. Ren Fail 2021;43:1408-15.

18 Zhu Y, Pandya BJ, Choi HK. Prevalence of gout and hyperuricemia in the US general population: the National health and nutrition examination survey 2007-2008. Arthritis Rheum 2011;63:3136-41.

19 Uchida S, Chang WX, Ota T, et al. Targeting Uric Acid and the Inhibition of Progression to End-Stage Renal Disease--A Propensity Score Analysis. PLoS One 2015;10:e0145506.

20 Kumar A U A, Browne LD, Li X, et al. Temporal trends in hyperuricaemia in the Irish health system from 2006-2014: a cohort study. PLoS One 2018;13:e0198197.

21 Kawamoto R, Kohara K, Tabara Y, et al. An association between body mass index and estimated glomerular filtration rate. Hypertens Res 2008;31:1559-64.

22 Shen W-wen, Chen H-mei, Chen $\mathrm{H}$, et al. Obesity-related glomerulopathy: body mass index and proteinuria. Clin J Am Soc Nephrol 2010;5:1401-9.

23 Wang Y, Chen X, Song Y, et al. Association between obesity and kidney disease: a systematic review and meta-analysis. Kidney Int 2008;73:19-33.

24 Fox CS, Larson MG, Leip EP, et al. Predictors of new-onset kidney disease in a community-based population. JAMA 2004;291:844-50.

25 Aune D, Sen A, Norat T, et al. Body mass index, abdominal fatness, and heart failure incidence and mortality: a systematic review and dose-response meta-analysis of prospective studies. Circulation 2016;133:639-49.

26 Pou KM, Massaro JM, Hoffmann U, et al. Visceral and subcutaneous adipose tissue volumes are cross-sectionally related to markers of inflammation and oxidative stress: the Framingham heart study. Circulation 2007;116:1234-41.

27 Hashimoto $\mathrm{Y}$, Tanaka M, Okada $\mathrm{H}$, et al. Metabolically healthy obesity and risk of incident CKD. Clin J Am Soc Nephrol 2015;10:578-83.

28 Sarathy $\mathrm{H}$, Henriquez G, Abramowitz MK, et al. Abdominal obesity, race and chronic kidney disease in young adults: results from NHANES 1999-2010. PLoS One 2016;11:e0153588.

29 Orlov NV, Makrogiannis S, Ferrucci L, et al. Differential aging signals in abdominal CT scans. Acad Radiol 2017;24:1535-43. 